\title{
THE POWER OF SYSTEMATIC DOUBT IN HISTORICAL ENQUIRY
}

\author{
Jan Vansina \\ Katolieke Universiteit te Leuven
}

\section{THE PROBLEM}

Many readers have probably noticed that the manuals of historical method which deal with verbal societies are primarily concerned with the sources available and the application of a critique to them. This is true for McCail's or Gabel and Bennett's works on Africa. But what is to be done with the sources once they are ready for evaluation remains vague. ${ }^{1}$ How does one reconstruct the past? How does one explain; or eventually interpret, history? Of the two works mentioned, only the first pays some attention to the question of 'historical synthesis.' McCall lists three possibilities: (a) that the sources support each other; (b) that they contradict each other; and (c) that they have no common reference or meeting point. This last situation is the most common in African history and indicates merely that not enough is known and that eventually new data could lead to new interpretative situations-either (a) or (b). The manual stresses that sources should be classified by discipline so that comparison of sources yields either confirmation or contradiction, with obvious and known data reinforcing the validity of the result. Once this is achieved it would seem that the job is finished, except for the warning that historical reconstruction requires a certain type of mind: imaginative yet disciplined. ${ }^{2}$

Yet the job is not finished. By comparing we have only established the degree of validity of reported events or situations. We have only verified how the observation, to borrow a term from the scientific experimental method, is correct. The impression remains that historical research is fairly mechanical: to find sources, subject them to a critique, assemble them. Reconstruction follows, with suitable use of imagination. That is the craft. Yet anyone who works with historical materials knows that that is not the practice of the craft. Josephine Tey's novel The Daughter of Time features a police sergeant who more nearly exemplifies historical practice-he guesses, ponders, backtracks, and finds sources almost by intuition. ${ }^{3}$ If he had made a few more mistakes he would have been a recognizable historian at work. A recent volume, The Historian's Workshop, though impressionistic, also yields a more realistic picture. ${ }^{4}$ In the real world historians start out with a hunch, an idea which leads them to an interest in documents or in oral traditions. Then the data suggest what Popper calls a historical interpretation"untestable points of view." The practitioner feels that the interpretation is not enough. It should be doubted and controlled by reference to more data until the point is reached at which no more control is possible. Then the historian feels satisfied with the result-even though it still remains an interpretation, because there remains the selective point of view implicit in the idea that initiated the research. ${ }^{5}$

The above sounds very much like a crude unsystematic version of the experimental method, especially as practiced in biology or medicine. A classic and particularly clear exposition of this method is given by Bernard. Biologists also start with an idea or an observation which gives them a hunch. If they begin with an idea, they proceed with an 
experiment to see what will happen. Once an observation has been made a hypothesis is elaborated. In essence it consists of a syllogism of the 'if-then' variety, often with the proviso 'all other things being equal'-ceteris paribus. This syllogism leads to a proposition which can be tested, a 'working hypothesis'. Testing is done by experiment or, in disciplines like astronomy, by observation. The experiments lead to confirmation, denial, or further elaboration of the hypothesis. Eventually this process, whether dialectic or not, should lead to confirmation of the hypothesis: 'if A, then B.' This hypothesis must then be subjected to counterproof, which consists of undertaking an experiment identical to the previous one in every respect save one: the suspected factor $A$ is suppressed. If, in the outcome of this experiment, result B does not appear, the hypothesis becomes a 'certainty' and eventually part of a theory'. But any theory must be abandoned if new facts that contradict the theory are brought to light. It must be replaced by one which will account for all the data. In such a case the historian usually settles on a compromise, but compromises seldom make for good theory. ${ }^{6}$ It is better to start again from the beginning; that is, to doubt all results and all theories until a new, simple, and uncontroverted theory can be framed. Bernard points out that the experimental method presupposes determinism. Even more important, he emphasizes the fruitfulness and fitness of systematic doubt. Hence his paradox "to have robust faith and not to believe." In the absolute sense it is true that determinism does not exist because "all other things" are never equal, and it is only when "all other things" are equal that the method works perfectly; ${ }^{8}$ however, experimental research does proceed in this fashion as is borne out by the history of progress in science itself, ${ }^{9}$ and the method is the principal reason for such progress. Historical enquiry seems to follow a similar course, so perhaps experimental reasoning could apply here as well: the detailed illustration of the process of historical enquiry which follows seems to support this conclusion. The handbooks of historical method should perhaps consider a variant of the experimental method as carefully as they consider historical critique or heuristics.

\section{AN ILLUSTRATION: THE KUBA}

Our own research among the Kuba of Zaïre did not start out as history. It became so when we began to understand that oral traditions were obvious historical sources. A corpus was assembled and historical critique applied to the different versions and variants of more than a thousand traditions. This led to a narrative descriptive history-a chronicle. The resulting evidence concerning origins was then compared with the linguistic and ethnographic data at hand. Everything dovetailed; here was a full observation. It was published. ${ }^{10}$ In particular, the Bushoong language was supposed to have been spoken by a majority of the population from the remote past and hence language affinity indicated affinity of population. ${ }^{11}$ The language was found most to resemble the speech of populations living west of the $\mathrm{Kuba}$, and this agreed both with the ethnographic distribution of matrilineal systems and with traditions of origin. ${ }^{12}$ The conclusions were drawn by introducing a compromise between diverging, albeit not contradictory, oral traditions, according to standard historical method. ${ }^{13}$ Yet those conclusions were all wrong.

As time passed it became clear that there was an error in dealing with the matter of language affinity. This first appeared in a lexicostatistical study carried out through a sophisticated statistical analysis. ${ }^{14}$ Bushoong was now seen to be closer to the language north of the Kuba than to that of the west. Further investigation, necessary now that disagreement had occurred, revealed that deeper morphological structures linked the 
language with the north, whereas phonological connections pointing to the west appeared to be more superficial. ${ }^{15}$ At this point it became clear that the traditions about 'origin' had to be revised. ${ }^{16}$

This became more important as it soon became known that one of the crucial traditional statements about the history of the peoples west of the Kuba was wrong. The royal traditions asserted that the Kuba had fought the Imbangala in the west before migrating; this could not be true since the Imbangala had never been there. ${ }^{17}$ No amount of compromise could disguise this fact. Once the truthfulness of the traditions was thrown open to question doubting proved extremely fruitful. To begin with, it revealed that Kuba 'truth' merely meant the consensus of the moment among political leaders and not that the tradition had remained unchanged as it was handed down over the generations.

Over the years since the first publication in 1957 of the results of Kuba field work, stimuli from other historians and anthropologists had provided both new data and new insights, and the conviction grew that the whole fabric of Kuba history should be reassessed, even though very few other studies referred specifically to the Kuba. Developments in the anthropology of cognition and in economic anthropology, the publication of several pre-colonial histories of other African societies, the general increase in our ethnographic knowledge of the areas surrounding the Kuba, a text edition of a document relating to the Kongo kingdom, and the stimulus given by the reexamination of Kuba chronology (prompted by a friendly discussion with a scholar) all played a role in these growing doubts. ${ }^{18}$ The last exercise really cemented this feeling by showing that there was still much to learn from data which had already been collected and analyzed.

Once doubt had entered the mind the questions mushroomed. Why this, why that? Why did the Kuba prefer one origin to another? It turned out that their cosmology favors one direction, and this emphasis can be discerned even in the plans of settlements and in the spatial aspects of ritual, belief, and some political institutions. Direction was dictated by cognition patterns. But (doubt again), could these themselves not have developed as a result of a genuine immigration from that very direction? Who was to tell? Here one ground to a halt. Meanwhile, doubting provided other dividends. It turns out that migration stories were created in various ways, and the ideal concept of migration for the Kuba explained the divergences between the traditions (which had been resolved earlier by compromise). It became possible to show that the only parts of the migration traditions that could tentatively be considered reliable were those concerning the last place in which the Kuba lived before settling in their present location; that is, due north, among people who spoke a northern dialect of the language family found to be presumably the most closely related to Bushoong. Once again, ironically, language and tradition were in accord. But meanwhile our whole conception of 'migration' had altered.

By this time the operational hypothesis had become that the language was northern until western influences changed obvious patterns in its phonology. The problem then became to determine how and when this might have occurred and to seek evidence for it. Kuba tradition relates that Shyaam, the founder of the latest dynasty, had travelled from (i.e., "came from") just those western areas indicated by the phonological similarities. Could it be that he had brought this new fashion in speech with him? If so, could that be confirmed? It could; ever since 1956 we had had dialectical evidence showing that western phonological features were most common in the center of the kingdom around the capital and court; while on the periphery these features were attenuated or wholly absent, so that a phonology of northern type prevailed even between the capital and the borders of the Kuba languages and the western ones in question! On logical grounds 
dialect geography concludes that in such cases the central feature is the most recent. ${ }^{19}$ So the conspicuous phonological features from the west must be more recent than those from the north. Whether or not Shyaam brought them with him, the evidence shows that they spread out from the capital, presumably from the court itself. Villagers probably adopted it in imitation of the prestigious court accent. Thus the dialect map reinforced the notion that there was a northern connection; when an archaic and meaningless term, found only in the royal salutation, turned out to be pure Mongo (northern) with an appropriate meaning, it no longer came as a surprise.

The observation about dialects led to yet another matter. The Kuba claim that they knew an archaic language at court called lambil. Only a few words of it have survived. Torday, who first recorded this claim in 1908, collected some lambil terms and believed that it had been an old language of the court and not Bantu. He confused it with the special royal language which also exists. ${ }^{20}$ Our own fieldwork showed lambil terms to be Bantu; a further collection of words seemed to lead nowhere. Some, such as kiing ('neck') were demonstrably archaic, since they appear in Common Bantu, but others were not. Now it occurred to me that lambil means 'speech of the mabil,' i.e., 'of the provinces' as opposed to the court. It seems that in the past the language at court was different, and this strengthens the evidence from the dialect map. If so, lambil terms ought to be northern and their replacements western. Although the results are still incomplete the present data support this hypothesis.

So it seems that Shyaam or his contemporaries introduced western features into the Kuba language. This suggests that features with northern affinities antedate Shyaam, who probably lived in the first half of the seventeenth century. Vocabulary can be used to separate features of society and culture of the earlier periods from the post-Shyaam period. Hence vocabulary analysis can serve to date oral traditions about these subjects and to provide new data as well. This procedure has yielded positive results. Wherever it has been tested, the hypothesis seems to hold, and by and large it stands when tested against the data supplied by comparative ethnography.

There are still difficulties in reconciling some data with the new hypothesis. The new linguistic data and the revised interpretation of the traditions place the proto-Kuba among the northern peoples, who are now all patrilineal, whereas the Kuba form part of the matrilineal belt. Were the Kuba once patrilineal or, conversely, were the northern groups once matrilineal? Did the Kuba perhaps become matrilineal on the advent of the latest dynasty, during or shortly after the time of Shyaam? This last supposition seems unlikely since we know of no changes in descent systems that were initiated merely by a change in the ruling line or even by political events in general. A study of the relevant terms indicates considerable innovation among the $K u b a$ and hints at a patrilineal organization for the proto-Kuba, but the data are as yet inconclusive. More detailed data from the northem areas may yet refine a point or two but will probably not contribute much more than that. The hypothesis of original patrilineality for the Kuba will remain a weak point simply because it cannot be tested further.

Semantics allow, then, a reconstruction of Kuba culture and society before Shyaam-indeed, before they left the area just north of their present location. Since the degree of validity of such reconstruction is closely related to the possibility of testing this hypothesis further, great care is taken to reconstruct those features that appear in an archeological context-layout of villages, shape and organization of houses, forms of pottery, burial practices, location of dumps, nutritional and agricultural data, and the like. Future excavation will be a test of the whole reconstruction. If, for instance, one finds compact villages, this will indicate that by that time kinship groups at the residential 
level were already weaker than the political principle governing the whole village, although this would not by itself indicate whether or not the Kuba were patrilineal. In short, the more experimentally verifiable a hypothesis of reconstruction becomes, the more worthy of consideration it will be.

The whole exercise of contrasting vocabulary items to be used as a control on traditions may seem to be circular reasoning-because traditions provided the basis for separating layers of vocabulary in the first place-but it is not really circular. The actual separation of vocabulary items occurs purely on comparative linguistic grounds and hence constitutes independent evidence when it is compared with traditional data dealing with one item or another. Such a dialectic process of enquiry does not seem reprehensible. On the contrary, it seems more desirable not to separate the different disciplines involved until the last moment before reconstruction, rather than to draw the distinctions earlier as McCall would prefer to do. ${ }^{21}$ An earlier separation is artificial in neglecting the impact of one finding on the other types of data analyzed and hence preventing the useful pursuit of the quest through the logic of successive hypotheses.

During this research in comparative vocabulary we found that an old African cereal, the one that most resembles maize (that is, sorghum), must have been cultivated here. Botanical evidence makes it clear that maize was a late introduction, since it was an American plant. This finding leads to two sets of considerations. The first is: if there was sorghum, how could it be grown in a forest environment with high humidity and a dry season only sixty days long? When had it to be planted and when harvested? Answers to these botanical questions have repercussions on the agricultural calendar and the study of productivity and perhaps of the division of labor as well. A question of vocabulary and a tradition concerning maize lead us to botanical evidence and agricultural economics.

The other consideration concerns a later period. Why did maize find favor? Because it stands higher moisture and can be double-cropped in a single year. This makes it possible almost to double the estimate of the supply of basic cereals available to the Kuba under the last dynasty. Was this a factor which helped make it possible to build such an elaborate political system? Or is the system responsible for driving up production? Or is there a dialectic involved? Probably the latter, since the comparative data from the western Lele indicate that when they adopted maize they lacked strong enough authority structures to demand higher production and hence harvested it only once a year. ${ }^{22}$

The importance of the data relating to crops warranted further research. The American origin of maize is attested to by botanical evidence and, for this part of Africa, by written data as well. Crop names tally with a hypothesis of diffusion from the Atlantic coast inland. The dates are plausible; they agree well with those known for the introduction of these crops on both sides of the Zaire river. The results thus become highly reliable.

Meanwhile the comparison of hundreds of words confirmed the close relationship of the Bushoong language with the north on a semantic level. The northern connection had been postulated at first mainly on the basis of morphological criteria. By now criteria from most levels of language-phonology, morphology, semantics-support it. That a feedback mechanism provided the semantic dimension to this does not alter its value, since the results stand by themselves. The original reasons for a comparison of vocabulary do not matter either; the comparison by itself is sufficient to strengthen the language hypothesis.

The situation of Shyaam now raises other questions, since it appears that massive innovations occurred during his reign. Was this due to him or was it not? The traditions make him a Culture Hero who created most of that which is specifically 'Kuba'. Perhaps 
his name came to be a convenient label attached to the memory of extensive changes that occurred under the reign of his immediate successors as well as his own-after all, oral tradition cannot remember any general change, anything that is not an event, except by personifying it. ${ }^{23}$ Variants of the tradition suggest that this supposition is true. Even so, why were so many novelties introduced in what seems to have been a relatively short time-no more than half a century? How did a foreigner from the west take power? These and other questions lead to the formulation of further hypotheses.

Exegesis of the traditions confirms that Shyaam was a foreigner because his mother (in some versions his father) was said to be a "slave" and long before Shyaam the term 'slave' meant 'foreigner', although the term also applied to the inhabitants the proto-Kuba found in the area they now occupy. 'Novelties' suggest trade, which leads to the observation that trade figures prominently in the accounts of the life of this Culture Hero, and, further, to a novel interpretation of a text dated ca. 1619. ${ }^{24}$ This text states that a European travelled two hundred (Portuguese) miles beyond the Kwango in search of Prester John. He returned because Kikongo was no longer understood in those parts. The mileage given for other distances in the same source is correct so it seems safe to infer that our traveler reached the very area from which Shyaam originated just a decade or two later. Perhaps this individual followed an established trade route, as so many after him did. The fact that he set out from a known major market and that Kikongo was understood so far away from Kongo country strengthens the suspicion of a trade route, since Kikongo was a trade language between Kongo and Kwilu long before $1880 .{ }^{25}$

The trade route hypothesis can be tested further. The museums of Copenhagen and Stockholm possess seventeenth century pile cloth very similar in manufacture and iconography to Kuba cloth from the 1890 s. The cloth came from the Kongo kingdom and, within it, from the very area beyond the Kwango to which our European travelled (as indicated by various texts). Since the Kuba claim that Shyaam brought pile cloth with him, it is not unreasonable to link all of this together and to claim that this cloth was made in the seventeenth century in the area through which the trade route to Kongo passed, the very area from which Shyaam set out to rule the Kuba. Further controls on this hypothesis yield positive results. The name for raffia cloth tends to link the Kuba and the west. The use of cloth (but not pile cloth) as currency is noteworthy because it is raffia cloth as well. But the word for 'market' does not substantiate a close general commercial relationship between the Kuba and their western neighbors. The term must be either an innovation or of northern origin. As for the names of the market week, even though all Kuba names are linked to one term which is one of the four names for market in the west, the week itself does not conform to the four day week in the west; hence three of the four names for the days are absent among the Kuba. ${ }^{26}$ This datum is valuable because it rules out the possibility of a gradual introduction of western vocabulary and phonology into the Kuba language by means of a trade sustained over several centuries. Trade there was, but its frequency and, probably, its volume were low, as indicated by the data for marketing days and currency.

This illustration can be pursued still further by following other threads, raising other operational doubts, and constructing further hypotheses. The illustration has been developed enough to indicate the following features:

a) whenever a suggestion turned into a hypothesis, it was framed into a syllogism of the 'if type so that it led to further testing, new observations, and an advance in knowledge whether or not the hypothesis was confirmed.

b) The further the chains of observation and hypothesis stretched, the wider the field of relevance became, so that a question about origins forced us finally to broaden our questioning to extend over the whole of Kuba history, and the questions that arose from framing hypotheses designed to test doubtful ideas led not only further in time 
but further in historical scope as well. Kuba history is growing far beyond a merely descriptive chronicle of events.

c) As a corollary of (b), the more progress that was made, the greater the number of different types of sources that came naturally into play. In the illustration oral tradition, linguistics, comparative ethnography, written data, iconography, botanical evidence, and agricultural economics entered into the scene seriatim.

d) Oral tradition remained dynamically central because of its assertions, the events it purported to describe. Each assertion fosters a doubt which leads to the framing of questions and then hypotheses.

\section{THE HYPOTHESIS}

The illustration demonstrates the fruitfulness and fitness of an approach which maintains a constant feedback between observation and hypothesis (to use the terminology of the experimental method) at the level of historical reconstitution. The illustration has not yet dealt at all with historical interpretation; it has not explained how and why events happen or situations arise. The illustration permits us only to deduce the requirements for establishing a hypothesis, the requirements for testing the value of an observation being given by the normal canons of historical criticism.

The form of reasoning in a hypothesis is clear, as the next instance shows. Major premiss: If , in this manuscript, all other mileages are correct, then the mileage given for the unknown distance will also be correct. Minor premiss: other mileages are observed to be correct. Conclusion: the mileage for the unknown distance is correct (ceteris paribus).

The major is the hypothesis. It has no validity if it does not lead to an observation in the minor. Otherwise no conclusion can be drawn and we have merely an opinion or an interpretation. The use of ceteris paribus is necessary. True, other things never are equal, but this is not enough to condemn the entire approach, since in other disciplines where the method is successful other things also are never really equal. ${ }^{27}$ A hypothesis is always a working hypothesis. The minor may contradict the major; then no conclusion can be drawn. If the minor confirms the major a theoretical statement derived from the major follows; in this case "all mileages given in this manuscript are correct."

The instance chosen is simple and straightforward, and hence rare. An examination of the major requires only calculation of the present-day equivalents of the other mileages and their degree of correspondence with the normal usage of the mile at the time the manuscript was written (determined by comparison with other contemporaneous manuscripts). The hypothesis remains fairly straightforward and factual.

Most hypotheses, though, even descriptive hypotheses, which try to establish merely whether events took place or whether a given situation existed, are more complex than this; for example,

Major:If the basic vocabulary of Kuba languages is related to that of northern languages, then the Kuba languages share a common ancestry with those of the north.

Here the major is in effect a general proposition, itself not an a priori statement, but the product of a long chain of syllogisms produced by the theory of historical linguistics-a theory induced from all known instances. It holds good for all languages studied everywhere, with a single exception, Mbugu. Because of this exception it cannot be regarded as a universal rule until the particularities which distinguish the exception are specifically eliminated from the hypothesis. The case then implies in its major a known or assumed general theory existing in another discipline and begins there. Ideally the whole of the problem of Mischsprache in historical linguistics should be checked before the major is stated. In reality the historian trusts the linguist because there is a consensus 
among linguists on this point. He must be prepared, however, to revise the major if the consensus disappears in the face of new evidence or observations. Therefore, even in descriptive matters in most cases historians are dependent upon generalizations derived from other disciplines. They must be aware of this and examine whether such generalizations are not only current theory but also, at least at the time, undisputed. This will avoid much naivete in research and at the level of historical explanation. Propositions such as that an increase in food leads to population explosion, and that the change from hunting and gathering to agriculture automatically leads to an increase in food supply are still assumptions made daily by historians but which, as demographers, nutritional human biologists, and economic anthropologists know, are unfounded.

In practice, then, the major premiss not only is the key to the enquiry but is often weak because its validity is in doubt. If such major propositions derive from experimental sciences the problem is not as great, because controversy in such disciplines is always settled by experiment and disputed questions represent the points of progress. Consequently, disputed points should not be used as major propositions. The situation in regard to major propositions derived from a social science theory is rather more delicate. Unfortunately, it is this situation that is most common. Only some of these disciplines (such as much of linguistics and most of economics) have developed methods based on strict reasoning (although in economics the experimental method is less used than a priori reasoning, which is proper to mathematics as well). The methods of archeology and art history are similar to the historical method and so their problems should be familiar to the historian. As in history, the rules for obtaining evidence are well developed, but with regard to interpretation a wide range of practices exist. In fact, a major debate in archeology rages about the limits of deduction possible from the data. ${ }^{28}$ Thus, some of the disciplines potentially most useful to historians do not provide generalizations that can be used as major propositions in syllogisms except at a modest level. In every case, it must be emphasized, the validity of these generalizations must be checked very carefully. They can never be taken for granted, even if there seems to be a consensus about them, which in fact is extremely rare in the social sciences.

The final step in the experimental method is the application of a counterproof. In its strictest form this cannot be done in history-one simply cannot replay the past minus one feature. Thus we cannot attain Bernard's "certainty".29 Situations cannot be reproduced even approximately, as they are in experimental psychology, pedagogy, medicine, and the like, where there are control groups to be used as counterproof. ${ }^{30}$ History can rely only on two approaches, even less rigorous than the use of control groups - the differential approach and the hypothetical counterproof.

Two paths are open for a differential approach. One can compare two situations that have grown out of the same ancestral situation or originally similar but diverging (even opposite) evolutions of societies and cultures without common ancestry. The first path would use the knowledge that Kuba and Lele developed from a single ancestral society. The Lele evolution is then used as a control for the Kuba. Since the Kuba developed intensive food production and a state and the Lele did neither, the proposition that state and productivity evolve in correlation would be upheld by the counterproof, the Lele case. But the control remains imperfect because the Lele did undergo a different evolution and did not remain unchanged as a control unit should.

The second path is the "comparative method." The Kuba proposition of a correlation between state and productivity could be tested by adducing evidence from societies with the same kind of environment (on the production side) sorted out into states and others (but what are 'others'?). The comparison could be worldwide and need 
not be tied to one time period. One could restrict it to African examples and a pre-industrial setting in order to reduce the number of imponderables, or at least to keep them as consistent as possible. To state the approach is to reveal its weaknesses. What is comparable and what is not? And how do we go about the mechanics of comparison? ${ }^{31}$ In the illustration only one allusion was made to such a situation: that descent systems are not imposed by a dynastic change. In fact, however, no one has examined all the available cases and the statement rests merely on the fact that if this exists at all it is not common.

The other approach to counterproof involves a reductio ad absurdum. If a process is proposed and if the contrary is very unlikely a high degree of plausibility (but never certainty) can be achieved. Kuba data showing that maize diffused from the west have been strengthened by the available tests, so the hypothesis seems to stand. The reductio counterproof would involve a diffusion from the Kuba to the west, the only other theory which would fit the known data. This involves the invention of a circuitous route from somewhere on the Atlantic coast far to the east and then doubling back west through Kuba territory to the coast again. There is no shred of evidence for such a route and the theory sins against the basic rules that the unknown cannot be used to explain the known and that the simplest explanation, involving the smallest number of steps, is the most likely. (In a purely deductive argument, as in mathematics, the simplest is called the most elegant solution.)

However inadequate a form of counterproof may be, one must be given, even if it is not explicit. ${ }^{32}$ It has been recognized that this may involve considerable nimbleness of mind: first to establish a hypothesis and strive to substantiate it, and then to strive equally carefully to destroy it. But this is no more difficult than to abstract conscious biases and this, difficult as it may be, can be achieved, as, for example, in Biblical studies. ${ }^{33}$ The fact remains that if a scholar is unable to supply a counterproof, his critics usually can. One of the positive roles of the critic is to check proposed theories for alternative explanations.

Once the counterproof is completed the experimental method is concluded. The hypothesis, if sustained, becomes 'theory', whether it be a minor or a general point. Thus, even a descriptive statement of evidence, " $x$ happened," is a theory. For the purposes of historical reconstruction (as distinct from historical explanation) there can be no doubt that the systematic use of a modified version of the experimental method will be beneficial, because it does help to find implicit postulates and to avoid muddled reasoning. Historical synthesis is not merely a "classification of facts" in which a hypothesis is only to be used as a last resort to fill gaps between the data. ${ }^{34}$ The hypothesis is the core of reasoning in history even at the simple descriptive level. In this sense the modified experimental method must be considered an extension of the historical method, which is all too often confined to historical critique alone. ${ }^{35}$

\section{THE UNFOLDING OF THE ENQUIRY}

One effect of the use of the scientific method on historical data is that it continually expands the area of applicability of the data through the sequence of hypothesis and observation until it encompasses the whole field of study undertaken; in this case, the whole reconstruction of Kuba history. In so doing it forces the researcher to recognize the inherent unity of his reconstruction, since the ramifications of any alteration run throughout the subject. A question of mistaken language identity leads to a reassessment of every period in Kuba history, not only of those near the seventeenth century. 
Strengthened and broadened conclusions about Shyaam's time lead to new questions about the relation of society at that time to society as it is thought to have been around 1900.

The method also clarifies, often painfully, where the gaps are. In the Kuba case one would like to know exactly how and when the cultivation of maize led to double-cropping and in turn to elaboration of the political structure (or at least increased tribute) or, indeed, whether there was a connection between these two phenomena at all. Obviously, to identify lacunae is important. Gaps must be bridged solely by interpretation, reasoning that really cannot be proven, and this is unsatisfactory. But at least to identify the weak spots is to make it possible for some other scholar perhaps to devise a tool to test the interpretation and make a hypothesis of it. The classical means of filling gaps is the argument from silence which, in a field "starred with lacunae," should never be used. ${ }^{36}$ Nor, indeed, should the argument by conjecture, which infers a causal bond between one datum and another, allowing extrapolation from a known datum to an unknown, be accepted. The elaboration of political institutions among the Kuba and the increase in their cereal production might be supposed to have a causal relationship, but it cannot be concluded that this is so, because there is no necessary link between the two. Other arguments, such as the argument by analogy or by retrospectivity (the first argues by comparison, the second postulates the relation between states of phenomena at different time periods) rely on social science models just as much as does the argument of conjecture.

Since in fact the historian always starts from an idea, it is perfectly valid to conceive of a theoretical model, to test it wherever possible, and to accept it if it survives counterproof. Such a model, in differing from the implicit view held about society and culture, will lead to the ideas that are the starting points of any enquiry. Two types of models can be developed. The best known is the 'null model' or 'zero method. ${ }^{37}$ These are best known in economics. Invoking a given, they will predict what a variation of its factors will cause. Deviations from the prediction do not lead to abandoning or even modifying the model, for the model is logical. Rather, deviations will be measured from the model now used as a standard of coordinates-a 'zero point'-and interpreted. Usually the economist attempts to account for discrepancies between expected and actual results by invoking aberrant forces or factors at work (claiming that all other things are not equal here). He then attempts to identify these aberrant forces and to find them again in other situations.

Sahlins' discussion of the application of Chayanov's rule concerning the amount of food produced in different peasant households is typical. ${ }^{38}$ Chayanov had derived this rule empirically from a large-scale study of Russian peasantry. Sahlins argued that it applies to all domestic modes of production; that is, to most pre-industrial societies. He tested it and found deviations. He reduced these to a common set of aberrant factors, which he identified in several cases he studied. It is clear that this type of purely logical model can be used to bridge a gap, always provided that the probability of deviations be recognized and that the analogical character of the exercise be stressed. It is very likely that at all times Kuba households produced different amounts of foodstuffs in accordance with Chayanov's rule and that the demands of political tribute somewhat altered this pattern in the way Sahlins found. But we are still dealing with a comparison, and the Kuba case probably contains some elements (such as joint labor of men and women) which are not identical to that factor of production in other cases.

The other type of model, much favored by social anthropologists, is a structuralfunctional abstraction built using patterns resulting from previous attempts based on case 
studies of given societies. Sometimes these are altered when new cases show a partial lack of correspondence between the model and the data. This occurred, for instance, with the model of segmentary societies developed first from the Nuer, then the Tiv, then altered to account for such cases as the Somali or the Libyan Bedouin and finally differentiated from other segmentary societies of different types such as the Tallensi. Except in the field of kinship studies where this refinement and partial replacement of models continues and yields a body of theory, models are often quickly discarded and replaced by others. Even within the narrow field of kinship studies several schools of thought coexist, such as the one which stresses the primordial character of the marriage alliance and that which stresses the same for descent groups. The tendency to discard models readily accounts for the irregularity of accumulation of social science theory and for outsiders often finding concepts more fruitful (as in sociology) than whole bodies of theory.

Nevertheless, such models are of primary importance. Not only do they raise questions or elucidate possible connections between phenomena, but they are also the best means of evolving material to bridge gaps in information. After all, history is a social science. Examples are easy to find. It is because of an existing model that we can tie the data about early Kuba society together and describe it as patrilineal, virilocal, and segmentary as far as kinship is concerned. Missing connections between bits of contemporary information are supplied by a comparison of all the cases kinship theory has encountered, and benefit from the logical structure of this theory. Kuba history deals in part with the process which turned this situation into a matrilineal society with a state structure. This was a major change. It is clearly focused as a problem because of existing models in anthropology. It is considered significant because such models incorporate a large number of analogies, some of which disagree with the Kuba case. Again, the models imply that the main impact of change was not a change from one type of descent system to another, but the shift from a residential group formed by males from the same corporate kin group to one instead in which a territorially based village authority came to be dominant.

Obviously, models are used for more than bridging gaps. They should be used as hypotheses and tests be performed to substantiate or refute them. The argument about Kuba residence patterns is supported by the appearance and etymology of a new term for 'clan' as well as by ethnographic evidence from the 'descendent' societies of 1900 . A refutation cannot merely dispute a point but must pose further questions-for example, how a process of change could otherwise have occurred. Equally obviously, however, such large-scale models can never be completely proven hypotheses in all their parts and therefore must remain the principal materials for historical 'interpretation'.

The application of the experimental method not only helps the historian to widen his perspective and to realize that his whole reconstruction will be part of a single cloth, but it should also help him to realize that his corkscrew movement between observation and hypothesis and the widened field of investigation that follows from it are not arbitrarily directed. There is a direction implicit in it that reflects the interests and imagination of the researcher, the concerns of his milieu, and the time available to him-in short, the subjective aspects of historical enquiry. The virtue of the method is simply to force the researcher to become aware of some of his assumptions about his interests by formulating specific 'if ... then' hypotheses. By becoming more conscious he will avoid many naive assumptions, although of course one never escapes one's milieu.

So far we have discussed conclusions (a) and (b) drawn from our illustration. The implications of (c)-that the evidence of different disciplines is drawn naturally into the enquiry-and (d)-that oral tradition seems to provide a central impetus by its 
assertions-can now be explored. These features suggest an orderly procedure for the collection of different types of evidence: begin with oral traditions and include othe evidence as required, for it is ancillary. ${ }^{39}$ It should be remembered, however, that : sound knowledge of the society involved and of its language is required even to begin th collection of traditions, so that anthropology and linguistics are already involved. Nc discipline is ancillary; all are equally involved and equally important.

Linguists, archeologists, social and cultural anthropologists, and biologists all stan out from the perspectives of their own disciplines, but historians begin with the kinds of evidence they are trained to find and evaluate-written and oral data. Other disciplines pursue their own goals-goals which may not be related to the historian's. For an astronomer, the calculation of dates for solar eclipses is a tedious chore, not research. For the historian this kind of data is the contribution of astronomy to his interests. Even in historical disciplines, however, the difference of goals raises unexpected difficulties, as between archeology and history.

Archeology deals with time and thus is a form of history. Yet in practice most archeologists in Africa are fascinated by antiquity. The Stone Age has attracted more interest than the Iron Age and the early Iron Age more than the later Iron Age, while the nineteenth century has proven least attractive of all. Consequently most archeological research has dealt with periods too early for historians who have (and can have) no other evidence about them. Often the Stone Age data "do not make sense" to historians; they do not recognize the problems and questions they are accustomed to dealing with. The situation mirrors the general division of labor between the two disciplines in Europe where prehistory ends when documents are excavated. True, there is overlap. Classical antiquity has been the subject of lively archeological research with many of the most reputable archeologists engaged in it. In the past few decades medieval sites have also been excavated, but they are still considered somehow to be of lesser importance than finds from the Roman or pre-Roman periods. In Africa, the last decade has witnessed a shift of interest from the earliest periods to the Iron Age. But the overlap with 'historical' periods is far from satisfactory and communication between the practitioners of the two disciplines is still often difficult. They are not well enough informed of their mutual goals, which are not identical. Most archeologists are interested in broad 'evolution' and most historians in unique sequences that can be causally explained.

One of the major subfields of linguistics is historical linguistics. Its main concern is to establish the genetic relationship between languages, and the time periods involved usually lie beyond the time spans of interest to historians. The latter are most interested in loan words, semantic innovation, and onomastics; these are of peripheral interest to most linguists. In social and cultural anthropology comparative ethnography is not pursued on the scale and with the impetus and encyclopedic approach historians would prefer because the comparative method in anthropology is usually worldwide and comparisons are made to elaborate or test general theoretical propositions. Regional comparative ethnography does not have a special niche in anthropology, to the detriment of historians. And the basic questions anthropologists ask are often differently directed from those of historians. This will be appreciated by anyone familiar with the literature on multilinear evolution or on socio-cultural change, two domains which fall within the range of historians' interest.

The solution is not to study all the disciplines the historian of verbal societies may have to use, but to consult with specialists in other disciplines. Historians must, however, be acquainted with those portions of other disciplines which they may need during their own research. They should certainly have a notion of the capacities of other disciplines so 
at questions can be framed for others to answer. One hopes that in time specialists in her disciplines will become more and more interested in historical problems, so that $y$ will begin with the contributions of their own disciplines and allow the historian to plain to them what he wants to learn. It will then become possible to initiate a research bject with such diverse data as linguistic analysis of loanwords and archeological finds. starting points, however, they will probably suffer from a serious drawback for the aightforward application of the historical method. Only written documents and oral dition assert that events occurred and hence afford a ready point of departure for a set doubts and hypotheses. A loanword or even the collective finds of an excavation are s specific in their evidential claims and therefore it will be more difficult to frame an propriate hypothesis.

Past experiences in Africa indicate that there exists a strong bond between oral, cheological, linguistic, and ethnographic evidence. The data are interrelated, but need search hypotheses framed to emphasize these connections. A recent instance of this mbiosis is the site in the Niger delta referred to by oral traditions, which yielded little pts identical with the 'ritual' tamuno pots of the place where the oral traditions figinated. The function of the pots is explained by ethnography, while archeology shows me continuity between this site and the place where the tradition was collected. 40

While archeological or linguistic data can sometimes serve as firm evidence, pmparative ethnography, although provocative, is too unconvincing to stand alone, as If a century of practice in historical anthropology has illustrated. ${ }^{41}$ To be accepted as iidence in most cases such data must either be joined by a parallel enquiry in semantics - must form complex arbitrary symbolic systems of their own which allow plausible Ionclusions. Even then, though, it usually is possible to obtain semantic evidence that will ponfirm or deny.

Empirical evidence shows at once that biological data can be very useful, but it also lemonstrates that the link between biology and history is often hidden. The historian must learn to develop a special feeling for framing questions about biology and should peek competent advice even in establishing a hypothesis. Thus, if tradition claims that forghum was planted by the proto-Kuba, it is not necessarily obvious to a historian that the environment was only marginally adequate for such a crop and that he must collect lata about temperature, humidity, rusts, soils, plant covers, and length of growing season, hot to mention nutritional results or the bio-energetical balance of cultivation. And yet all of these are obvious to the agricultural economist. Clues in our evidence that it is time to seek advice are mentions of plants or animals and also of changes in man's organic behavior or natural environment. As an organism man has heredity, adapts to an environment, is subject to disease, requires a certain, nutritional level, and reproduces himself. Whenever a question arises which involves any of these functions, advice should be sought from the appropriate quarter in order even to comprehend the problem involved. Since all history deals with man it is clear that in fact the bond between these disciplines and history ought to be strong and made use of frequently. That it is not is simply the result of mutual neglect. How often do we ask ourselves whether the environment of, say, the proto-Kuba was infected with trypanosomiasis, or how clearing may have affected anopheles breeding and hence the spread of malaria, or whether the introduction of maize upset the previous dietary balance in such a way that the fecundity rate was increased? This network of bonds between biology and history will have to be developed and intensified by both sides. ${ }^{42}$ Unlike the cases of other kinds of evidence already discussed, the solution of teamwork is clearly impractical. Only the special sensitivities developed by the historian will help. 
It is in this area of consultation with specialists from other disciplines that the historian will benefit particularly from an application of the experimental method, because this method literally forces him to phrase a hypothesis and to reflect upon whether it will stand as a generalization. More often than not this will be the first inkling he will have that he needs help.

\section{THE EXPERIMENTAL METHOD AND HISTORICAL EXPLANATION}

So far the discussion has been limited to historical description or "the reconstitution of the facts," though this may in itself imply a choice and a direction. To go beyond description to understanding one must go beyond the unique even if the case being examined is in fact sui generis. ${ }^{43}$ Several levels of generalization can be achieved, and again the experimental method contributes more than is usually assumed. A rule in Kuba history seems to dictate that a king's sons should benefit from their father's incumbency, since although a king could use them as his deputies during his reign succession is matrilineal. When the father dies the sons stand to lose many of their privileges and most of their power so that their vested interest lies in keeping him on the throne. Once the succession takes place the sons of the deceased ruler ally themselves with the new king's heir apparent. The new king and his children in turn try to oust the sons of the late monarch and strife follows. The intensity of this strife depends on the amount of power the old king has given to his sons and the privileges associated with it. As a proposition this model can be tested. All the succession disputes in which sons are mentioned confirm this 'rule' as does the behavior of some kings toward their predecessor's sons. Not a single contradictory case can be found. Moreover, there is a rough correlation between the increase in privileges for royal children and the harshness of treatment meted to them by succeeding kings. The rule holds and we have a valid generalization, albeit on a modest scale.

At a further but still essential level, causal relationships are involved. Did the Kubs political system develop as a result of increased productivity precipitated by the introduction of maize or did the political system stimulate increased productivity by the imposition of taxes? Or was the whole a dialectic relationship primed by one or the other? Or was there no direct relationship at all? The last alternative is certainly the weakest. There are too many kinds of tribute collectors (especially of food) in the system to take it seriously. Sahlins generalizes that production will intensify wherever political structures develop toward a 'state' system. The relationship can then become dialectic. Comparative data from Lele and Kuba support the notion of a link, as Mary Douglas has persuasively demonstrated. 44 Traditions are of course vague, attributing economic innovation (the introduction of maize) to a particular king, but it could hardly be otherwise. Sahlins' rule, however, implies a whole theory of systematic underproduction in a non-state society resulting from his "Domestic Mode of Production." The Kuba example neither contradicts nor substantiates this. With the introduction of maize and its higher yield and double-cropping, the Domestic Mode of Production was inevitably altered. A test is no longer possible, nor is a counterproof, beyond the correlation already indicated. The whole generalization can then be treated only as an interpretation, not as a real hypothesis. Does it at least have an explanatory value? It does insofar as Sahlins' rule is general. But we realize at the same time that we have reached a limit. Without any attempt at experimental control we could not discern the difference between such a plausible interpretation and a substantiated hypothesis. In the strict sense of the word the invocation of Sahlins's rule in the Kuba case is not a theory. It is rather an interpretation 
that will stand only until another, equivalent generalization is conceived. It obviously could not itself serve as the foundation for a further elaboration, whereas a theory could.

History tends toward causal generalizations. It is at this level that most objections have been made to the application of scientific methods in history. This is primarily because the experimental method involves the criterion of determinism and its corollary, predictability. But without determinism systematic doubt could not exist and, as we have seen, in practice doubt can prove extremely fruitful. It is the engine that renovates and improves our understanding of the past. Without being drawn into a discussion of "the science of history" it may suffice to point out the predictability is general rather than concrete for every case because of the ceteris paribus proviso (which, as we recall, never really applies). Futhermore, determinism is sociological, not philosophical, and certainty means in practice only high probability.

This whole debate about ultimates should not prevent us from adopting a useful practice-the tidy form of reasoning and doubting and proving that is the experimental method. Nor should it bother us unduly that experiment and counterproof can never be in historical enquiry what they are in some other disciplines, as long as the method proves to be fruitful. Fruitful it can be, not only at the descriptive level but precisely at this higher level of causal explanation which must be reached if history is to be meaningful.

Perhaps its greatest virtue is to remind the historian that his major hypotheses are all derived from other sciences and that none of us can afford to proffer explanations without the slightest idea whether the generalizations make sense in other disciplines. ${ }^{45}$ This is also true for the general historian. Let him not invoke population explosion or the desire to control valuable resources or the envy of a ruler as causes if he does not at least realize that these are linked at the very least with demography, the problem of economic rationality, or individual psychology. His causal explanations will stand or fall by their plausibility in terms of these other disciplines as well as in terms of the general plausibility of their internal logic and their relationship to the data. This is all the more important for the history of verbal societies because of the diversity, yet paucity, of the sources. The diversity increases the danger that a historian literally may not understand what he is writing about and pile one doubtful fact on another, thereby multiplying rather than reducing his chances of error. ${ }^{46} \mathrm{He}$ also may not realize how high he jumps when he strives for his conclusions, the causal explanations. By applying the experimental method most of these pitfalls can be avoided, even if some of the glamor of ringing conclusions must be forsaken. For the method will make clear the exact extent of the doubts and the inferences inherent in the explanations.

In particular, the method implies that years will elapse before a piece of research can be finished completely and also that it would be wiser if more than one mind ponders the problems. Both of these considerations dictate that publication should not be delayed until all the results are in. To delay is only human; who wants to stand in error? And yet it is bad policy, for the time lag delays progress in our field as a whole and increases the possibility that in the end nothing at all will be published. To delay publication can indeed add to the chance of error, since constructive criticism is thereby muzzled. For these reasons we do not regret having published a Kuba history based only on oral tradition, even though we now are the first to realize its inadequacy. Presently we will include more and different data in a new attempt. But without excavations the archeological implications of the hypotheses advanced can only be suggested. If, one day, an archeologist does excavate we may once again stand in error, but the history of this part of the world will gain from it. 


\section{CONCLUSIONS}

This essay has attempted to apply a variant of the experimental method to historical enquiry. It argues that this is the most natural and most fruitful way to approach a historical question. In particular it holds that doubt framed in suitable hypothetical statements is valuable in exploring avenues of research, in revealing weaknesses, in laying bare hidden assumptions. Methodical doubt is the way to knowledge.

\section{NOTES}

1. D.F. McCall, Africa in Time Perspective: A Discussion of Historical Reconstruction from Unwritten Sources (Boston, 1964); C. Gabel and N.R. Bennett, eds., Reconstructing African Culture History (Boston, 1967). These works are not alone; all treatises we know of have neglected this aspect of historical method. They give a few hints or leave the matter to philosophers of history. See such works as J. Le Goff and P. Nora, eds., Faire de l'histoire, 3 vols. (Paris, 1974), or the older C. Samaran, L'histoire et ses méthodes (Paris, 1961). The latest (15th) edition of the Encyclopaedia Britannica: Macrapaedia, 8:958, recognizes that "the critical operations on the sources are merely preliminaries and the work of the historian proper only begins when he attempts a synthesis of his materials." But the prescription given only repeats that historians must muster up sympathy with the subjects under study (debatable!), mentions imaginative insight, and concludes that "ideally, a historian must display capacities akin to those of a poet or an artist." This kind of conclusion is both common and obnoxious. The 'art of healing' hampered scientific, i.e. experimental, medicine considerably. The 'art of history' may well prevent further methodological elaboration of the whole process of enquiry. There will always remain an imaginative part to historical research, just as there is in all sciences, but that truth should not be used to cut off all further discussion, as so commonly happens.

2. McCall, Africa in Time Perspective, pp. 145-55.

3. J. Tey, The Daughter of Time (London, 1951).

4. L.P. Curtis, Jr., ed., The Historian's Workshop: Original Essays by Sixteen Historians (New York, 1970 ).

5. K. Popper, The Poverty of Historicism (London, 1957), pp. 150-1. The general point that ideas or theories always precede observation is accepted by all philosophers of science and by historians. There cannot be a 'pure' inductive method.

6. C. Bernard, Introduction à l'étude de la médicine expérimentale (Paris, 1966 [original edition, 1865 ]), pt. I, pp. 29-93. This section is divided into two parts: "Observation and Experiment," and "A Priori Ideas and Doubt in Experimental Reasoning." A typical example of compromise is the famous article by $R$. Oliver, "The Problem of the Bantu Expansion," JAH, 7 (1966), pp. 361-76, which conciliates two apparently contradictory linguistic theories. Despite its ingenuity and brilliant insights its major weakness now appears clearly to have derived from the simple juxtaposition of these theories.

7. Bernard, Introduction, p. 234. Bernard explains that if we can be certain on the one hand that determinism exists we can on the other hand never be certain that we have found it.

8. This is true of any concrete situation, whether it be in physics, economics, or history. Hence the deterministic principles advanced cannot apply totally and all the factors involved in bringing about the concrete situation cannot be anticipated.

9. E.g., A. Einstein and L. Infeld, Die Evolution der Physik: von Newton bis zur Quantentheorie (Hamburg, 1956) for a classic exposition. Confirming the point is S. Benison, Tom Rivers: Reflections on a Life in Medicine and Science (Cambridge, Mass., 1967).

10. J. Vansina, Geschiedenis van de Kuba van ongeveer 1500 tot 1904 (Tervuren, 1963). 
11. The Bushoong language is spoken by the central group of the central Kuba languages, all of which are dialects of it or closely related to it. The Bushoong ruled the kingdom conventionally labelled 'Kuba'.

12. Vansina, Geschiedenis, pp. 246-7; J. Daeleman, "Vergelijkende studie over enkele Noordwestelijke Bantoetalen" (unpublished diss., Leuven, 1956).

13. Vansina, Geschiedenis, pp. 110, 135, 251-2.

14. E. Evrard, Etude statistique sur les affinités de cinquante-huit dialectes bantous: statistique et analyse linguistique (Strasburg, 1966), pp. 85-94.

15. J. Vansina, "Les langues bantoues et l'histoire: le cas Kuba" in A. Ménier, ed., Melanges offerts à Hubert Deschamps, in press.

16. J. Vansina, "Traditions of Genesis," $J A H, 15$ (1974).

17. J.C. Miller, "Kings and Kinsmen: The Imbangala Impact of the Mbundu of Angola" (unpublished diss., University of Wisconsin, 1971).

18. The impact of theories in social sciences, especially anthropology, is to be expected, as is the influence of colleagues and friends. Inspiration derived from other historical works is not so evident, but every man is an imitator; furthermore, other works often grapple with similar problems. Hence A.D. Roberts, A History of the Bemba (London, 1973) is the latest of a series of works which have acted as stimuli to revise the Kuba case.

19. On the same grounds as the age-area hypothesis in biology and anthropology; for the latter see $\mathrm{H}$. Hickerson, The Chippewa and Their Neighbors: $A$ Study in Ethnohistory (New York, 1970), pp. 21-4.

20. E. Torday and T.A. Joyce, Notes ethnographiques sur les peuples communément appelés Bakuba, ainsi que sur les peuplades apparentees, les Bushongo (Brussels, 1910), pp. 32, 37, 43, 109, $255-7$.

21. McCall, Africa in Time Perspective, p. 144.

22. M. Douglas, "Lele Economy Compared with the Bushoong: A Study of Economic Backwardness" in P. Bohannan and G. Dalton, eds., Markets in Africa (Evanston, 1962), pp. 211-33, esp. 219-21.

23. D.P. Henige, The Chronology of Oral Tradition (Oxford, 1974), pp. 34-6.

24. F. Bontinck, "Histoire du royaume du Congo (ca. 1624)," Etudes d'histoire Africaine, 4 (1972), pp. 5-145, esp. 63, 133. For the date see pp. 21-3.

25. H.W. Fehderau, The Origin and Development of. Kituba (Lingua Frana Kikongo) (Kisingani, 1967).

26. J. Vansina, "Probing the Past of the Lower Kwilu Peoples (Zaire)," Paideuma, 19/20 (1973/74), p. 351.

27. Popper, Poverty of Historicism, pp. 93-4, points out that even when experimenting in physics "other things are usually not equal." He argues (p. 62) that social science can establish hypotheses analogous to those in the natural sciences. See also pp. 59-62.

28. For archeology compare M.I. Finley, "Archeology and History," Daedalus, No. 100 (1971), pp. 169-74, and L. and S. Binford, eds., New Perspectives in Archeology (Chicago, 1968), pp. 16-27. The most extreme position in the laxest sense may still be K.V. Flannery and M.C. Coe, "Social and Economic Systems in Formative Mesoamerica," in Binford and Binford, eds, New Perspectives, pp. 267-83. This wide-ranging kind of interpretation has become fairly common recently but the strictures of Finley have yet to be refuted successfully.

29. Bernard, Introduction, pp. 91, 182. 
30. Ibid., p. 182-5, would call this comparative experiment. At pp. 253-6 Bernard cites examples showing that the comparative experiment is ordinarily used as a counterproof. For control groups in medicine see Benison, Tom Rivers, passim.

31. The comparative method is still a major point of debate in anthropology. Can true comparibility be achieved and, if so, how? R. Narroll and R. Chen, eds., A Handbook of Method in Cultural Anthropology (New York, 1970) devote pp. 581-1003 to this problem. See. J.F. Köbben, "Comparitivists and Non-Comparativists in Anthropology," ibid., pp. 581-96, for a discussion of the various positions.

32. Bernard, Introduction, pp. 2534, speaks of a "consigne" and illustrates how a counterproof seemed to be completely superfluous, yet when the experiment was concluded the results were entirely unexpected. The counterproof by reasoning is perfectly valid. Popper, Poverty of Historicism, p. 95, speaks of an "experiment in imagination." He shows the crucial role of the counterproof in establishing theory (ibid., pp. iiin and 131-6). "Precisely because it is our purpose to establish theories as well as we can it is imperative that we test them as severely as possible. We must try to find fault with them and to falsify them. Only if we are unable to falsify them despite our best efforts can we say that they have stood the test. This is why instances confirming a theory mean little if we have not tried (and failed) to discover refutations" (ibid., pp. 133-4).

33. H. Clavier, "Remarques sur la méthode en theologie biblique," Novum Testamentum (1972), p. 182 , recalls the necessity for such scholars to "suspend judgment," to put personal conviction aside for the duration of the research, to practice the Epoche of the phenomenologists. See also ibid., p. 189.

34. L. Genicot, Critique historique (Louvain, 1964), p. 49, considers it as a last resort. The hypothesis must represent "the only conceivable explanation today of the established facts." This clearly is impossible and too positivistic.

35. Popper, Poverty of Historicism, p. 151, admits the possibility of formulating true hypotheses in history but argues that most historical "approaches" or "points of view" cannot be tested. At the descriptive level one must disagree but at the level of historical causal understanding he may well be correct, especially since, for him, history deals only with the unique (p. 143)-a point of view we cannot accept. Therefore we do not believe that historical causal explanation will always remain as vague and untestable as it often is now. E.H. Carr, What Is History? (New York, 1961), pp. 75-6, feels that the status of the hypotheses used by the historian is remarkably similar to that of those of the scientist.

36. J.B. Bury, Selected Essays (Cambridge, 1930), p. 52.

37. Popper, Poverty of Historicism, p. 141. For Popper the zero method assumes complete rationality and estimation of deviations. The second operation is required in principle only in economics where the first is assumed by the hypothesis ('rational' being defined by the model).

38. M. Sahlins, Stone Age Economics (Chicago, 1972), pp. 87-92, 102-22.

39. McCall, Africa in Time Perspective, pp. 144-55, differs considerably from this approach. I know of no other specific discussion on this matter except for general statements about teamwork and interdisciplinary support.

40. E.J. Alagoa, “Oral Tradition and Archaeology,” Oduma, 1 (1973), pp. 10-2.

41. C.A. Schmitz, Historische Volkerkunde (Frankfurt, 1967) is an excellent reader, especially on the German schools. See Hickerson, Chippewa, pp. 18-33, for a discussion of the American schools of thought.

42. The prescription is easily uttered. Only the production of actual articles and monographs which stress the impact of these biological factors will in fact develop our awareness. When will we have an African analogue of H. Zinsser, Rats, Lice and History (Boston, 1935)? Only a bestseller of this kind can help us break through, especially in the field of medicine. 
43. All philosophers of history and historians who write handbooks argue that history explains by showing recurring and/or unique causes. Beyond this opinions differ sharply as, for instance, can be seen by comparing Popper, Poverty of Historicism, pp. 143-52 and Can, What Is History?, pp. 113-43 (to take two recent examples). At the level of small regularities of the type that follows, agreement still obtains, but broad generalization is primarily a function of philosophical conviction. The 'meaning of history' remains the a priori philosophy of the historian.

44. Douglas, "Lele Economy"; Sahlins, Stone Age Economics, pp. 130-48. The position of Sahlins presupposes the acceptance of his definitions of 'state', which in turn are dependent on the acceptance of a multilinear evolutionary theory. Needless to say, his proposal clashes with standard Marxian thought. Yet on this point it would seem that a worldwide study including counterproof or refutation analysis should be able to come to more than a vague 'interpretation'.

45. Popper, Poverty of Historicism, pp. 144-6, stresses the reliance on other disciplines but does not grasp how truly frequent and general this is, even at the simplest level of descriptive history. Other philosophers of history maintain a similar position.

46. J.R. Harlan and J.M.J. de Wet, "On the Quality of the Evidence for the Origin and Dispersal of Cultivated Plants," Current Anthropology, 14 (1973), p. 54, discuss the probabilities regarding "items of dubious quality." 